\title{
EXPOSURE TO CHLORPHENVINPHOS, AN ORGANOPHOSPHATE INSECTICIDE, PREVENTS FROM BEHAVIORAL SENSITIZATION TO AMPHETAMINE
}

\section{PIOTR LUTZ ${ }^{1}$, DOROTA WIADERNA ${ }^{1}$, SLAWOMIR GRALEWICZ ${ }^{1}$, and BARBARA KUR ${ }^{2}$}

${ }^{1}$ Department of Toxicology and Carcinogenesis

${ }^{2}$ Department of Immunotoxicology

Nofer Institute of Occupational Medicine

Łódź, Poland

\begin{abstract}
Objectives: Exposure to organophosphorus (OP) pesticides, irreversible inhibitors of acetylcholinesterase (AChE), may result in long-lasting alterations in the functional state of the central nervous system. In earlier studies, we found that a single exposure of the rat to chlorphenvinphos (CVP), an OP pesticide, made the animal hyposensitive to amphetamine (AMPH) three weeks posttreatment. A repeated administration of AMPH is known to result in a progressive increase in the behavioral sensitivity to the psychostimulant. It makes it likely that treatment with AMPH after the CVP exposure may result in amelioration of the CVP-induced hyposensitivity to the psychostymulant. The purpose of the present experiment was to check out this supposition. Materials and Methods: At the first stage, the relationship between the CVP dose and the effect on sensitivity to AMPH was tested. The rats were given CVP once intraperitoneally (i.p.) at a dose of $0.0,1.0$ or $3.0 \mathrm{mg} / \mathrm{kg}$. Three weeks later their open field behavior was assessed before and after i.p. administration of $0.25,0.5$ or $1.0 \mathrm{mg} / \mathrm{kg}$ of AMPH. At the subsequent stage, the susceptibility of the CVP-treated rats to AMPH sensitization by repeated AMPH treatment was investigated. For this purpose each of the rats was repeatedly treated with AMPH in its home cage (one injection/day for five days). At stage two, the daily AMPH dose received by each animal was of the same magnitude as that received at stage one. Two weeks after the last AMPH treatment dose, the motor response to a test AMPH dose $(0.5 \mathrm{mg} / \mathrm{kg})$ was measured in all rats. Results: The results of stage one confirmed a significant reduction of behavioral sensitivity to AMPH in the CVP-treated rats. The results of stage two indicated that the CVP-induced decrease in sensitivity to AMPH was not ameliorated by a repeated treatment with AMPH at any of the used doses. In fact, in the rats exposed to the high CVP dose, repeated treatment with AMPH resulted, dose dependently, in augmenting of the depressive effect of the pesticide. Conclusions: It appears then that treatment to an OP pesticide reduces the rat's sensitivity to AMPH and makes the animal resistant to sensitization by repeated treatment with the psychostimulant.
\end{abstract}

Key words:

Chlorphenvinphos, Acetylcholinesterase, Amphetamine, Sensitization, Rat

\section{INTRODUCTION}

Epidemiological studies and clinical observations indicate that exposure to organophosphorus (OP) pesticides, inhibitors of acetylcholinesterase (AChE), may result in persisting neurobehavioral disturbances, the mechanism of which is poorly understood [1]. Some years ago we found that a single intraperitoneal (i.p.) exposure of the rat to chlorphenvinphos (CVP), an OP insecticide, resulted in the decreased behavioral sensitivity to amphetamine (AMPH). The decrease was detected in a test performed three weeks after treatment, i.e. after time long enough for the recovery of

This study was performed under the Project of the Nofer Institute of Occupational Medicine (No 1.18 / 01-03).

Received: May 5, 2006. Accepted: June 7, 2006.

Address reprint requests to Dr P. Lutz, PhD, Department of Toxicology and Carcinogenesis, Nofer Institute of Occupational Medicine, św. Teresy 8, 91-348 Łódź, Poland (e-mail: astra@imp.lodz.pl). 
ChE activity in blood and in the brain [2]. Therefore, this may be regarded as an experimental confirmation of the presence of long-lasting alterations in the central nervous system (CNS) functions after OP treatment. Since AMPH is an indirect dopaminergic agonist, the reduced behavioral sensitivity to this drug may indicate a lasting change in the functions of the dopaminergic system. It is well known that a repeated or even single treatment to AMPH or cocaine may result in a progressive and persistent increase in behavioral sensitivity to AMPH and that this increase is also related with some alterations in the dopaminergic system [3]. The reciprocity of long-lasting consequences of the OP exposure and AMPH treatment allows one to expect that the lasting CVP-induced decrease in behavioral sensitivity to AMPH may be ameliorated by AMPH treatment. The purpose of the present study was twofold. First, we wanted to confirm the suppressive effect of CVP treatment on the behavioral sensitivity to AMPH. In the previous studies [2], only one dose of CVP $(1.0 \mathrm{mg} / \mathrm{kg}$, i.e. about $1 / 10$ DL50) was tested and only one test dose of AMPH $(1.0 \mathrm{mg} / \mathrm{kg})$ was used for testing the effect of the exposure. According to some reports, opposite effects in the responsiveness to a test substance may be produced by week and strong "stressors" [4,5]. It makes it likely that a high dose of CVP, resulting in a full set of symptoms of organophosphate intoxication, would affect sensitivity to AMPH in a different way than the $1.0 \mathrm{mg} / \mathrm{kg}$ dose. Therefore, in the first part of the experiment, the behavioral response to various doses of AMPH was compared in the rats poisoned once to a low $(1.0 \mathrm{mg} / \mathrm{kg})$ or a high $(3.0 \mathrm{mg} / \mathrm{kg})$ dose of CVP. The second goal of the study was to find out whether and how the effect of CVP poison on the behavioral sensitivity to AMPH can be modified by repeated AMPH treatment, i.e. we tried to learn whether CVP exposure influenced the rat susceptibility to sensitization by repeated AMPH treatment. The obtained results indicate that CVP treatment, at low or high dose alike, reduces the rat's behavioral sensitivity to AMPH and makes the animal resistant to sensitization by repeated treatment with the psychostimulant.

\section{MATERIALS AND METHODS}

\section{Animals}

The experiment was performed on male outbreed Wistar rats from the breeding facility of the Nofer Institute of Occupational Medicine, Łódź, Poland. The rats were 3-4 months old and weighed 320-350 g at the experiment onset. For two weeks preceding the experiment and throughout the experiment they were housed in single rat cages at $22^{\circ} \mathrm{C} \pm 0.5^{\circ} \mathrm{C}$, with a light/dark cycle of $12 / 12 \mathrm{~h}$ (light on at 06:00). Standard rat food pellets (Murigran) and tap water were accessible ad libitum. Body weight (b.w.) was measured routinely once a week and before each injection. All experimental procedures have been approved by the Local Ethical Commission and were carried out by suitably qualified personnel.

\section{Chemicals and doses}

The following compounds were used in the experiment: chlorphenvinphos [(2-chloro-1(2,4-dichlorophenyl) vinyl dietylphosphate] and d-amphetamine (d-amphetamine sulphate). CVP (98\% active substance in concentrate) obtained from ORGANIKA-AZOT Jaworzno (Poland) (CAS REG [2701-86-2]) and AMPH purchased from SIGMA (Germany) (CAS REG [51-63-8]). CVP was diluted in sterile olive oil, and AMPH was dissolved in physiological saline (SAL). All solutions were prepared directly before use and given i.p. at the $1.0 \mathrm{ml} / \mathrm{kg}$ volume. CVP was given only once in a dose of $1.0 \mathrm{mg} / \mathrm{kg}$ or $3.0 \mathrm{mg} / \mathrm{kg}$. AMPH was administered in the following doses: $0.25,0.50$ or $1.00 \mathrm{mg} / \mathrm{kg}$ ).

\section{Biochemical assays}

In the biochemical part of this experiment red blood cell $\mathrm{AChE}$ (rbcAChE) and plasma cholinesterase (ChE) were determined before and after CVP administration. The determinations were performed on 18 rats divided into three groups ( $\mathrm{n}=6$ in each group): one control and two pesticide groups. The control group (group $\mathrm{O}$ ) was injected olive oil and the pesticide groups received CVP at a dose of $1.0 \mathrm{mg} / \mathrm{kg}$ (group P1) or $3.0 \mathrm{mg} / \mathrm{kg}$ (group P3). For determination of $\mathrm{ChE}$ activity, samples of peripheral blood 
were drawn from the tail vein (by the nick technique) into heparinized glass capillary tubes at the following time points: on day 7 before treatment, 3 to $4 \mathrm{~h}$ after the experiment and then on posttreatment days (PED) 7, 14, and 21. ChE activity was determined by the modified Ellman's colorimetric method [6], described in detail in an earlier report from this laboratory [7].

\section{Behavioral tests}

The behavioral part of the study was performed on 72 rats separated into nine groups as specified further in the text. The experiment was run at two stages. At stage one, we investigated whether and in what manner the acute treatment with CVP at a low $(1.0 \mathrm{mg} / \mathrm{kg})$ or a high $(3.0 \mathrm{mg} / \mathrm{kg})$ dose affected the rat's behavioral response to AMPH challenge after retun to normal activity of rbcAChE. At stage two, the rats were repeatedly treated with AMPH in order to sensitize them to the psychostimulant.

Apparatus. The rat motoric activity was assessed with use of a computerized 4-unit set of activity chambers (PROFEX Ltd, Białystok, Poland). The set was located in a room, $6 \cdot 2 \cdot 3 \mathrm{~m}$, neighboring the animal rooms. It was illuminated with a row of four white luminescence bulbs located at the ceiling. The ambient temperature and humidity inside the test room were the same as in the animal rooms. Each activity chamber (i.e. the open field) consisted of clear acrylic box $(63 \bullet 63 \bullet 40 \mathrm{~cm})$ with 2 tiers of infrared motion sensors spaced $2.5 \mathrm{~cm}$ apart. The first and second tiers of sensors were located 4.0 and $15.0 \mathrm{~cm}$, respectively, above the floor level. Each cage was equipped with a calculating system, which transformed the beam interruptions into the location of the animal within the cage 5 times/s. Raw data were stored in the cage memory. After the end of each test session the cage memory content was downloaded to a computer memory and subjected to further analysis with the computer-aided program (PC software "Rat", version 1.50, 2005). A state with no beam interruptions for at least $1 \mathrm{~s}$ was classified as "rest". Horizontal shifts of the rat's body equal or longer than $4 \mathrm{~cm}$ were regarded as ambulatory movements (AM). Shifts shorter than $4 \mathrm{~cm}$ were regarded as non-ambulatory (short-distance) movements (NAM). Interrup- tion of at least one beam of the upper tier of sensors was counted as a rearing episode. All measurements of locomotor activity were conducted between 08:00 and 14:00. For activity testing the rats were first weighed. Then they were transported to the test room and placed gently in the test cages. Each test session in the activity cages consisted of two separate measurements: the preinjection measurement and the postinjection measurement, each lasting $50 \mathrm{~min}$. After the preinjection measurement, the rat was transferred to its home cage standing on a rack nearby and the floor of the activity cage was cleaned with wet cloth. Then the rat received an injection and was placed again in the activity cage for the postinjection measurement. The interval between preinjection and postinjection measurement lasted 8-10 min.

\section{Experimental procedure at stage one (testing sensitivity} to AMPH). At the beginning of the experiment, all animals were habituated to the activity cages for two days, 30 min a day, with a 7-day interval between sessions. Then the test session, denoted as session 0 , was run. In this session, after the preinjection measurement, all rats were injected with SAL. Based on their body weight and activity measurements in session 0 , the animals were divided into nine groups ( $\mathrm{n}=8$ in each group): three control groups, $\mathrm{O} / \mathrm{A}-0.25, \mathrm{O} / \mathrm{A}-0.5$ and $\mathrm{O} / \mathrm{A}-1.0$, received pure oil, and six pesticide groups, of which three, $\mathrm{P} 1 / \mathrm{A}-0.25, \mathrm{P} 1 / \mathrm{A}-0.5$ and $\mathrm{P} 1 / \mathrm{A}-1.0$, received CVP at the dose of $1.0 \mathrm{mg} / \mathrm{kg}$ and the remaining three, $\mathrm{P} 3 / \mathrm{A}-0.25$, P3/A-0.5 and P3/A-1.0, were injected with CVP at a dose of $3.0 \mathrm{mg} / \mathrm{kg}$. Care was taken to make the groups as similar as possible with respect to the means of body weight and the activity scores in session 0 . The rats were injected oil or CVP only once two or three days after session 0 . The injection took place in a room neighboring the animal room. Immediately after the injection, the rat was placed in a cage, identical with its home cage, but with no bedding (wood shavings), where it stayed for about $3.5 \mathrm{~h}$. Afterwards, it was returned to its home cage in the animal room. The behavioral response to AMPH was assessed in the test session (session 1), which was run on day 21 after the administration of oil or CVP. In this session, the challenge dose of AMPH was $0.25 \mathrm{mg} / \mathrm{kg}$ in 
groups $\mathrm{O} / \mathrm{A}-0.25, \mathrm{P} 1 / \mathrm{A}-0.25$, and $\mathrm{P} 3 / \mathrm{A}-0.25 ; 0.5 \mathrm{mg} / \mathrm{kg}$ in groups $\mathrm{O} / \mathrm{A}-0.5, \mathrm{P} 1 / \mathrm{A}-0.5$, and $\mathrm{P} 3 / \mathrm{A}-0.5$; and $1.0 \mathrm{mg} / \mathrm{kg}$ in groups $\mathrm{O} / \mathrm{A}-1.0, \mathrm{P} 1 / \mathrm{A}-1.0$, and $\mathrm{P} 3 / \mathrm{A}-1.0$. Two days later, the next session (session 2) was run with SAL as the challenge drug.

Experimental procedure at stage two (sensitization induction). The second stage of the experiment started a day after session 2. To assess the susceptibility to sensitization by $\mathrm{AMPH}$, each rat received five injections of the psychostimulant (one injection/day for five successive days) at the same dose as it received in session 2, i.e. $0.25,0.5$ or $1.0 \mathrm{mg} / \mathrm{kg}$. The rats were returned to their home cages immediately after the injections where they were left undisturbed till the next injection. Two weeks after the last treatment with AMPH dose, the test session (session 3) in the activity cages was run. In this session, the rats were challenged with AMPH at a dose of $0.5 \mathrm{mg} / \mathrm{kg}$, same for all animals. Two days later the last test session (session 4) was run with SAL as the challenge drug.

\section{Statistical analysis}

For statistical comparisons the values of the body weight measurements and $\mathrm{ChE}$ activity determinations were expressed as the percentage of direct preexposure values. In the behavioral part, the following indices of behavior in the activity cages were compared: the distance covered during ambulation (DIS), the number of ambulatory movements, the number of rearings ( $R$ ), and the number of short-distance non-ambulatory movements. The raw preinjection (pre) and postinjection (post) scores and, additionally, the postinjection scores expressed as a percentage of respective preinjection scores (\%) were analyzed. A two-way ANOVA (groups - sessions) was employed. When a significant interaction was found, it was followed by one-way ANOVA and Tukey's test for pairwise comparisons. In case of non-homogeneity of covariance, an approximation procedure that avoids assumption about equal covariance, was applied. In this procedure, the degrees of freedom used in finding the critical values are reduced, which makes the test more conservative. Differences were regarded as significant when the probability of the null hypothesis was $5 \%$ or less [8].

\section{RESULTS}

\section{Body weight}

Figure 1 illustrates changes in the b.w. of rats investigated in the behavioral part of the experiment. The data encompasing the period between CVP (or oil) treatment and the first AMPH administration (session 1) were only taken into account. As the diagram shows, treatment with CVP at a dose of $1.0 \mathrm{mg} / \mathrm{kg}$ failed to exert a marked effect on b.w. (at no time point rats of the $\mathrm{P} 1$ groups differed significantly from those given oil alone). Treatment with CVP at the $3.0 \mathrm{mg} / \mathrm{kg}$ dose resulted in a significant but transient decrease in b.w. up to PED 7. After that time, the rats regained weight at a rate similar to that in the control and P1 groups. Thus, till the end of the experiment, b.w. of the rats treated with CVP at a dose of $3.0 \mathrm{mg} / \mathrm{kg}$ was significantly lower.

\section{ChE activity}

Figure 2 illustrates the changes in ChE activity after treatment with CVP (or oil), which were found in the biochemical part of the experiment. 3-4 h after the pesticide administration, ChE activity in erythrocytes was depressed by $55.2 \%,( \pm 10.1 \%)$ and $78.0 \%( \pm 2.5 \%)$ in the $\mathrm{P} 1$ and $\mathrm{P} 3$

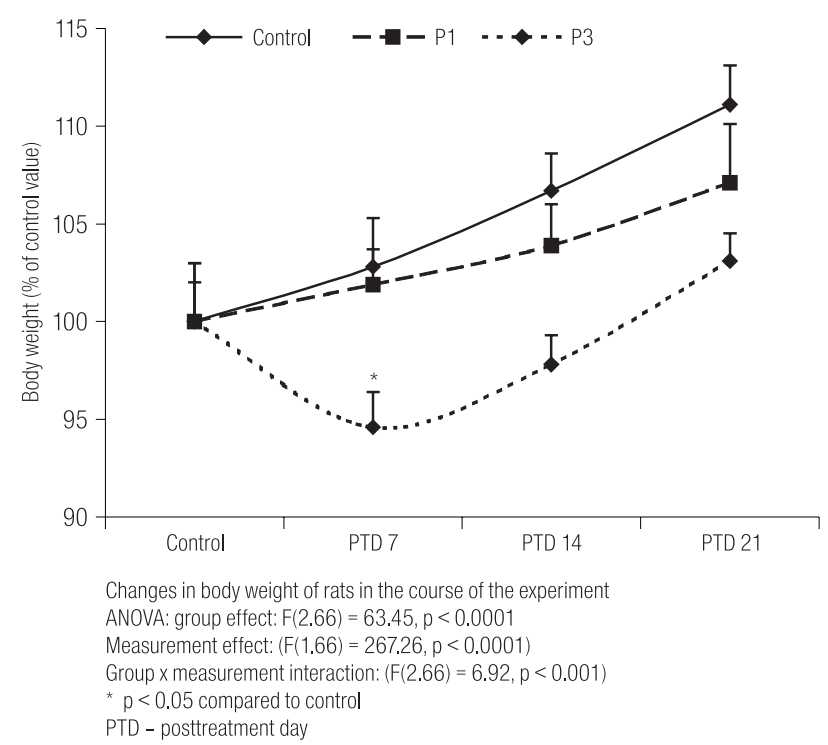

Fig. 1. Changes in the body weight of rats treated with: CVP at a dose of $1.0 \mathrm{mg} / \mathrm{kg}$ (group P1) or $3.0 \mathrm{mg} / \mathrm{kg}$ (group P3) and the pure oil control group used in the behavioral part of the experiment to the first administration of amphetamine. Body weight was measured seven days before and after treatment on posttreatment days 7, 14 and 21 . 

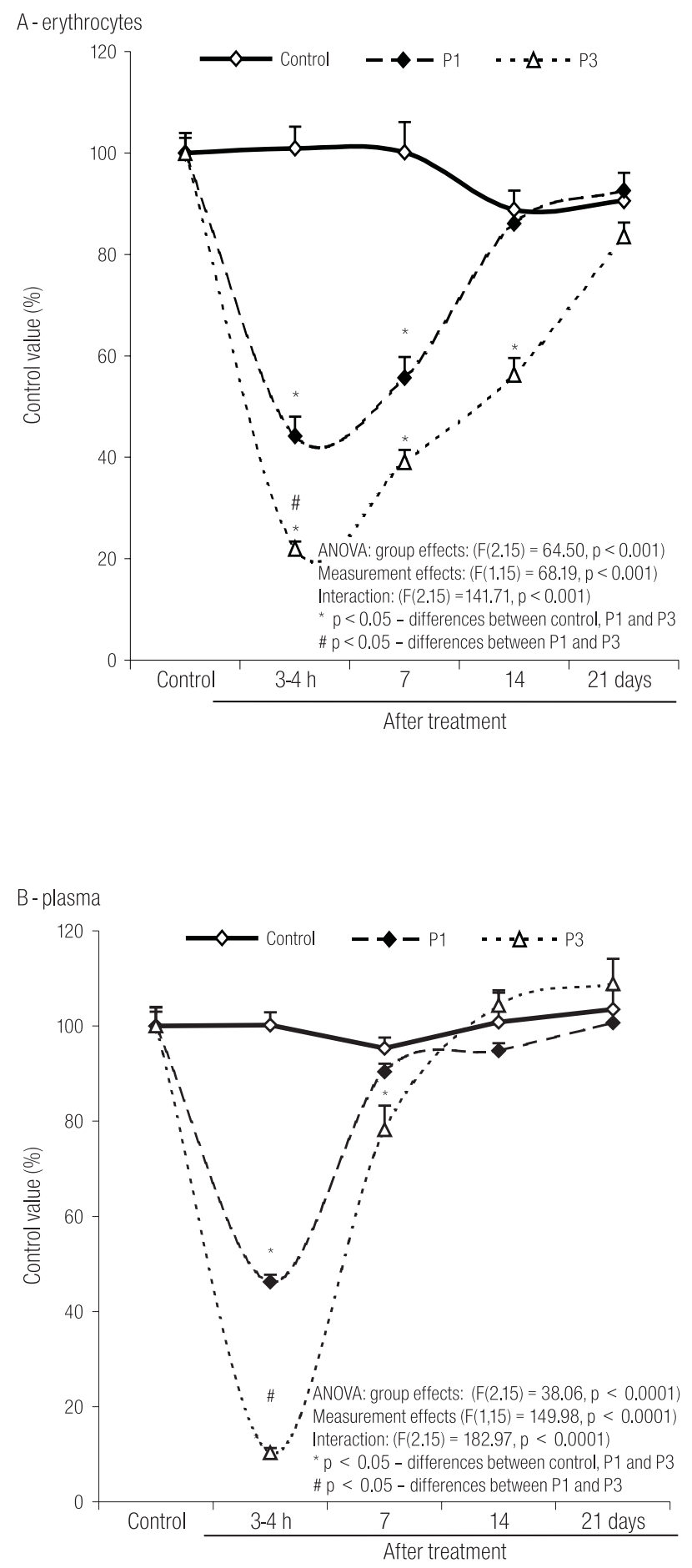

Fig. 2. Changes in $\mathrm{ChE}$ activity in erythrocytes and plasma in the rats treated with CVP: $1.0 \mathrm{mg} / \mathrm{kg}$ (group P1) or $3.0 \mathrm{mg} / \mathrm{kg}$ (group P3) and the pure oil control group. ChE activity was measured at the following time points: seven days before treatment (control) and after treatment: at the time of maximum enzyme inhibition (i.e. $3-4 \mathrm{~h}$ after pesticide treatment) and then on posttreatment days 7,14 and 21. Unrelated pretreatment values of enzymes activity (Ul) regarded as $100 \%$ : Relative values of $\mathrm{ChE}$ activity measured in erythrocytes (part A): the control group $0.8214 \pm 0.101$, group P1 $-0.7986 \pm 0.098$ and group P3 $-0.8401 \pm 0.131$ and in plasma (part B): the control group $-0.2891 \pm 0.211$, group $\mathrm{P} 1-0.3048 \pm 0.145$ and group $\mathrm{P} 3-0.2991 \pm 0.129$ ( $\mathrm{n}=6$ in each group). groups, respectively. The corresponding values for plasma ChE activity were $52.2 \%( \pm 2.14 \%)$ and $90.8 \%( \pm 1.2 \%)$. In both pesticide groups, $\mathrm{ChE}$ activity in plasma returned to the pretreatment levels faster than that in erythrocytes; on PTD 7 the recovery was complete in group P1 and almost complete in group $\mathrm{P} 3$. What concerns $\mathrm{ChE}$ activity in erythrocytes, the recovery was complete in groups $\mathrm{P} 1$ and P3 by PTD 14 and PTD 21, respectively. Thus, three weeks after CVP treatment, ChE activity in erythrocytes and in plasma were in both pesticide groups at the same level as in the control group.

\section{Behavioral results of stage one (sensitivity to AMPH after treatment)}

Data from both stages of the experiment were analyzed simultaneously. For clarity, however, the results concerning each stage are described separately. The results concerning the first stage are presented below.

Ambulatory activity (distance). The total distance covered by rats during the preinjection, 50-min measurements ranged from 35 to $65 \mathrm{~m}$. A comparison of DIS (pre) values showed no differences between groups in session 0 and session 2. In session 1, however, the pesticide-treated rats appeared less active than the control rats, although not in all cases the differences attained statistical significance (Fig. 3A). Like in the case of DIS (pre) values, no differences between groups were found in DIS (post) values in sessions 0 and 2 (Fig. 3B). Differences appeared in session 1. In most cases DIS (post) values in this session were higher than DIS (pre) values, and the magnitude of this increase was clearly dependent on the psychostimulant dose and the type of exposure (oil or CVP). In none of the groups challenged with the $0.25 \mathrm{mg} / \mathrm{kg}$ dose of AMPH, DIS (post) values in session 1 differed significantly from DIS (post) values in sessions 0 and 2, indicating that $0.25 \mathrm{mg} / \mathrm{kg}$ of AMPH was a subthreshold dose for an overt effect on locomotion. Of the three groups challenged with the $0.5 \mathrm{mg} / \mathrm{kg}$ dose of AMPH, groups O/A-0.5 and $\mathrm{P} 3 / \mathrm{A}-0.5$ showed an increase in locomotor activity; in both these groups DIS (post) values in session 1 were significantly (twofold or more) higher than in sessions 0 and 2 and did not differ one from another. In group P1/A- 0.5 , 
however, the effect of AMPH on locomotion was negligible: in session 1, the DIS (post) value was significantly smaller in this group than in group O/A-0.5 and did not differ significantly from DIS (post) values in sessions 0 , and 2. In all three groups tested with the $1.0 \mathrm{mg} / \mathrm{kg} \mathrm{AMPH}$ dose in session 1 the locomotion stimulating effect of the psychostimulant was evident, but in the pesticide groups it was markedly reduced; in both these groups, DIS (post) values in session 1 were significantly lower than in the O/A-1.0 group. In group P3/A-1.0, the DIS (post) value in session 1 was lower than in group P1/A-1.0, but this difference did not attain statistical significance. Comparisons of DIS (\%) values (Fig. 3C) revealed no significant differences related to the exposure. In each triad of the groups, the response to AMPH was best pronounced in the group challenged with the $1.0 \mathrm{mg} / \mathrm{kg}$ dose of the psychostimulant, but no differences between groups challenged with the same AMPH dose were found.

\section{Ambulatory activity (the number of ambulatory movements). The analyses of AM and DIS showed the same values (data not shown)}

Nonambulatory horizontal activity (short distance movements). In this experiment the NAM measurements produced the least variable values. NAM (post) values were usually within the same range (350-450) as NAM (pre) ones. In control groups the NAM data suggested a relationship between the AMPH dose and the NAM (post) number (i.e. the higher the AMPH dose the smaller the NAM (post) number). The results obtained in the pesticide groups suggested no relationship between NAM values and the treatment level or the AMPH test dose; no reliable statistical differences were found (data not shown). Vertical activity (rearings). The R measurements yielded the most variable results. An analysis of the R (pre) data suggests a persistent suppression of the spontaneous vertical activity in the pesticide groups, particularly in the P3 ones; in all these groups the $\mathrm{R}$ (pre) value in session 1 was significantly lower than in session 0 . There was no change in the vertical activity in any group challenged with the lowest test dose of AMPH in session 1. In the groups challenged with higher doses an overt response, i.e. increase in
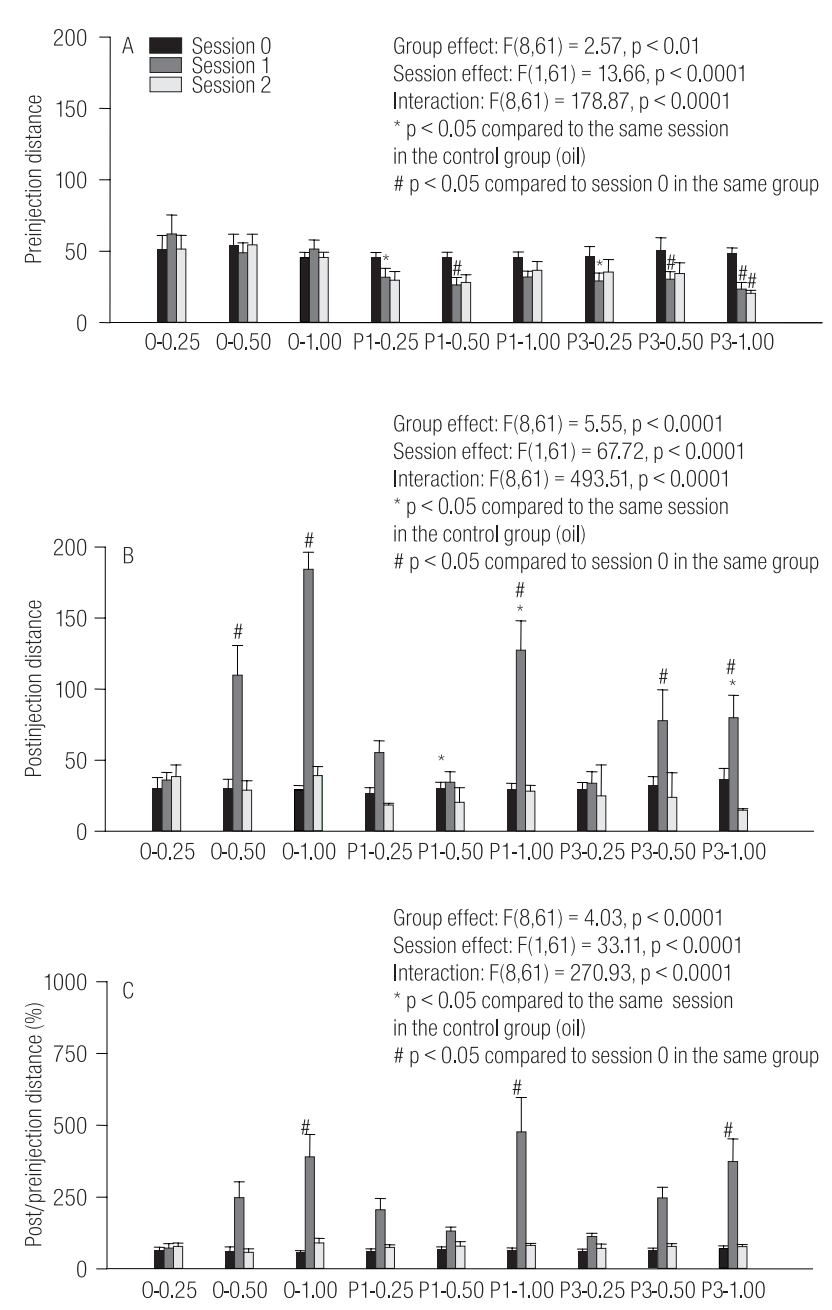

Fig. 3. Behavioral reactivity to amphetamine after CVP treatment. The diagrams show locomotor activity of the rats (traveled distance in $\mathrm{m}$ ) in sessions 0,1 and 2. Every session consisted of two 50-min measurements, before and after challenge. Measurements of session 0 performed 1-2 days before CVP treatment at a dose of 1.0 or $3.0 \mathrm{mg} / \mathrm{kg}$ i.p., session $1-21$ days after challenge, session 2 - 22 days after CVP treatment. Physiological saline challenge $(1.0 \mathrm{ml} / \mathrm{kg}$ i.p. $)$ was used in sessions 0 and 2 , amphetamine challenge $(0.25,0.5$ or $1.0 \mathrm{mg} / \mathrm{kg}$ i.p.) was used in session 1 . Part A - activity before injection (challenge), part B - activity after injection (challenge), part $\mathrm{C}$ - magnitude of change after challenge [(activity before challenge/activity after challenge) $\bullet$ 100]. The first part of the group name (before dash): 0 - control groups, $\mathrm{P} 1$ and P2 - groups treated with CVP at a dose of 1.0 or $3.0 \mathrm{mg} / \mathrm{kg}$, respectively. The second part of the group name (after dash) - the AMPH dose administered in session 1.

The results of the statistical analysis are given in near graphs.

the $\mathrm{R}$ number, appeared in groups $\mathrm{O} / \mathrm{A}-0.5, \mathrm{O} / \mathrm{A}-1.0, \mathrm{P} 1 /$ $\mathrm{A}-1.0$ and $\mathrm{P} 3 / \mathrm{A}-0.5$. However, the mean $\mathrm{R}$ (post) values in these groups were similar. No effects of AMPH was noted in groups P1/A-0.5 and P3/A-1.0 (data not shown). 

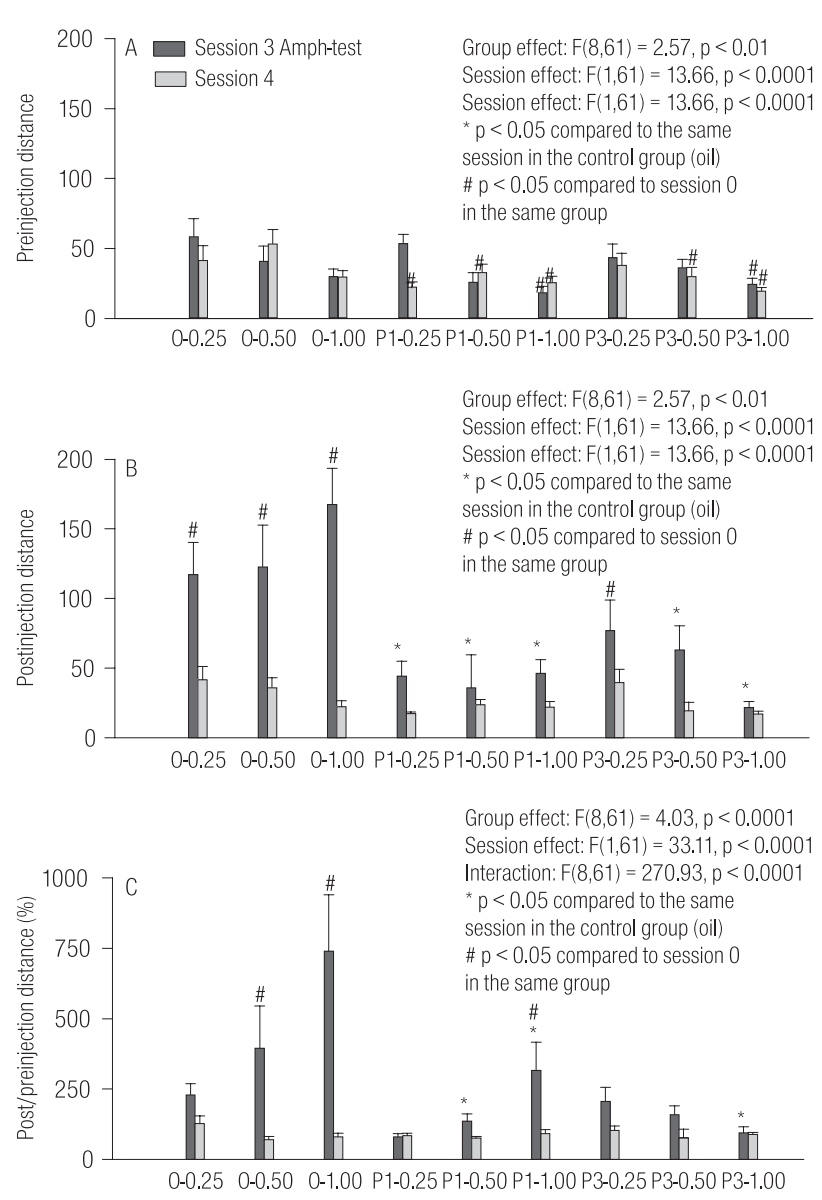

Fig. 4. Susceptibility to amphetamine after CVP treatment. 22 days after CVP administration $(1.0$ or $3.0 \mathrm{mg} / \mathrm{kg})$; the rats were treated with amphetamine $(0.25,0.5$ or $1.0 \mathrm{mg} / \mathrm{kg})$ for 5 successive days. The diagrams show locomotor activity of the rats (traveled distance in $\mathrm{m}$ ) in sessions 3 and 4 . Session 3 was performed on day 14, session 4 - on day 15 after the last dose of amphetamine. Amphetamine challenge $(0.5 \mathrm{mg} / \mathrm{kg})$ was used in session 3 and physiological saline challenge in session 4. The last part of the description as in Fig. 3.

\section{Stage two. Susceptibility to sensitization by AMPH}

Ambulation (distance). Comparisons of the DIS (pre) data from sessions 3 and 4 (i.e. sessions performed on days 14 and 16, respectively, after the repeated AMPH treatment) revealed no significant differences between groups or between sessions in any of the nine groups (Fig. 4A). The analysis of the DIS (post) (Fig. 4B) as well as DIS (\%) data (Fig. 4C) showed that two weeks after the repeated treatment with AMPH the control groups were most responsive to the test AMPH dose. In session 3, there were no significant differences between groups in DIS (post) values. Comparisons of DIS (\%) values suggest, however, that group O/A-1.0 responded to the test AMPH dose significantly stronger than groups $\mathrm{O} / \mathrm{A}-0.25$ and $\mathrm{O} / \mathrm{A}-0.5$ although in the latter the difference was not significant. (This "amplification" of the differences was certainly due to juxtaposition of two effects of the repeated AMPH treatment: the decrease in spontaneous activity and a dose-dependent posttreatment increase in the sensitivity to AMPH). It is worth stressing that in the O/A-1.0 group, the DIS (post) value in session 3 was almost of the same magnitude as in session 1. Considering that in this group the AMPH dose administered in session 3 consisted only $50 \%$ of that administered in session 1 , the similarity of the DIS (post) values in these sessions indicate that the repeated treatment with $\mathrm{AMPH}$ at the $1.0 \mathrm{mg} / \mathrm{kg}$ doses sufficed to sensitize the control animals to the locomotor effect of the psychostimulant. It was apparently not the case in the pesticide groups. In each of the groups given $1.0 \mathrm{mg} / \mathrm{kg}$ of CVP, the response to AMPH in session 3 was significantly (two to three times) weaker than in the corresponding control (oil) groups. What is more, these groups did not differ between themselves in the response to AMPH. In the groups pretreated with the $3.0 \mathrm{mg} / \mathrm{kg}$ dose of CVP the situation was different. In these groups, like in groups pretreated with $1.0 \mathrm{mg} / \mathrm{kg}$ of CVP, in session 3, DIS (post) values were lower (significantly in groups P3-0.5 and P3-1.0) than in corresponding oil groups. These groups, however, differed significantly between themselves in the magnitude of the response to AMPH. Judging on the basis of DIS (post) values, rats of the P3-0.25 group were most, and those of the P3-1.0 group least sensitive. In the latter group DIS (post) values were significantly lower than in the P3-0.25 and P1-1.0 groups. They were also lower than those in group P3-0.5 in session 1 (before repeated treatment with AMPH).

This result indicates that in group P3-1.0, repeated treatment with AMPH was not followed by an increase in the sensitivity to the psychostimulant. To the contrary, it resulted in an exacerbation of the suppressive effect of CVP treatment. In other words, treatment with CVP not only makes the animal persistently hyposensitive to the locomotion-stimulating effect of AMPH and renders it less susceptible to sensitization behaviorally by repeated 
AMPH treatment, but it may also promote the development of hyposensitivity to AMPH upon a repetitive treatment with the psychostimulant.

\section{DISCUSSION}

In the presented study, CVP-induced changes in AChE activity and body weight did not differ from those obtained earlier in this laboratory [7,9]. The behavioral effects of exposure, i.e. decreased spontaneous locomotor activity (noted in the preinjection parts of sessions 2 and 3 ) and reduced response to AMPH challenge, were also similar [2]. However, a broader range of doses employed in the present study allows for a better characterization of the latter effect. The results of session 1 (assessment of the posttreatment sensitivity to AMPH) indicate that in the control groups the relationship between the administered psychostimulant test dose and the postinjection locomotor activity was nearly linear. In the CVP-exposed groups, however, the dose-effect relationship was poor, which might be due at least in part to large within-group differences.

The results of the second part of the experiment (sensitization induction) showed that the repeated dosing with AMPH resulted, dose dependently, in a decrease in spontaneous motility. It also resulted in an increase in behavioral sensitivity to AMPH, but only in the control group treated repeatedly with the highest AMPH dose $(1.0 \mathrm{mg} / \mathrm{kg})$. Animals of the low pesticide groups appeared totally unsusceptible to sensitization by repeated AMPH administration. In the high pesticide groups, the situation was even more intriguing; the results suggest that repeated treatment with the highest AMPH dose resulted in the exacerbated effect of the pesticide. To sum up, the obtained data suggest that rats exposed acutely to CVP at the applied doses develop hyposensitivity to AMPH and become resistant to sensitization by repeated treatment with the psychostimulant.

The essential question emerging from the above results concerns the likely neuronal basis of the aforesaid effects. There are at least two possibilities worthy of consideration. One of them are long-lasting functional alterations in the central cholinergic system, which can develop after CVP treatment. As suggested by Overstreet et al. [10] a decreased behavioral sensitivity to AMPH goes along with cholinergic hypersensitivity. It has recently been shown that exposure to cholinesterase inhibitors is followed weeks later by an increase in excitability of cholinergically innervated limbic structures and an exaggerated conditioned fear response [11,12]. It is possible then that treatment with CVP triggered the process leading to a persistent increase in the cholinergic tone, which might explain the results of the present experiment.

The other likely cause of hyposensitivity to AMPH and the reduced propensity to become sensitized by repeated AMPH treatment may be an alteration in the functional state of the hypothalamo-pituitary-adrenal (HPA) axis. This possibility is suggested by the following facts. First, it is known that the HPA axis contributes substantially to the behavioral effects of psychostimulants; it has been shown that adrenalectomy or inhibition of the corticosterone synthesis decreases the behavioral sensitivity to AMPH and prevents from sensitization by an AMPH treatment [13-15]. Second, there is no doubt that AChE inhibitors are powerful stressors, i.e. they activate the HPA axis $[16,17]$. In experiments performed in this laboratory on rats, CVP given i.p. at a dose of 1.0 or $3.0 \mathrm{mg} / \mathrm{kg}$ resulted in a sevenfold increase in plasma CORT concentration $3 \mathrm{~h}$ after the pesticide administration [18]. Third, it has been shown in numerous studies that exposure to physical or psychological stressors [19], or simply repeated or even single administration of corticosterone or the synthetic corticoid dexamethazone [20] may result in a decreased CORT and ACTH response to a test stressor. The suppression was noted 48 h, 7 days or even 28 days after stressing and in response to homotypic or heterotypic test stressors [18,21-25]. According to some authors, the stressor-induced decrease in the responsiveness of the HPA axis is a consequence of the transient corticosterone hypersecretion $[19,20]$. As already mentioned, administration of $1.0 \mathrm{mg} / \mathrm{kg}$ CVP results in manifold increase in serum CORT concentration, which makes it likely that CVP intoxication, like exposure to other stressors, results in a long-lasting suppression in HPA responsiveness. Such an effect might account for both the diminished locomo- 
tor response to AMPH and the reduced susceptibility to sensitization by repeated AMPH administration. Unfortunately, at present we are not aware of any data on the long-term changes in the HPA axis reactivity following CVP treatment and to the best of our knowledge there are no relevant literature reports concerning this issue. It is worth mentioning here, however, that in humans the psychological alterations following treatment to AChE inhibitors resemble those observed in posttraumatic stress disorder (PTSD) [26,27] and the PTSD is characterized by cortisolemia and an enhanced negative feedback sensitivity of the HPA axis [28-30].

A weak point of the above interpretations lies in the absence of a clear-cut difference in magnitude of the alterations produced by the $1.0 \mathrm{mg} / \mathrm{kg}$ and $3.0 \mathrm{mg} / \mathrm{kg}$ doses of CVP. However, we have recently shown that after the $3.0 \mathrm{mg} / \mathrm{kg}$ dose of CVP the rise in CORT level was similar in magnitude to that observed after the $1.0 \mathrm{mg} / \mathrm{kg}$ dose of CVP. This may indicate that the $1.0 \mathrm{mg} / \mathrm{kg}$ dose was sufficient to induce the maximum effect at least as far as the CORT level is concerned. This may explain why the effects of dosing with $1.0 \mathrm{mg} / \mathrm{kg}$ or $3.0 \mathrm{mg} / \mathrm{kg}$ of CVP did not differ substantially. A strong point of both assumptions, i.e. linking the effects following CVP treatment to changes in the cholinergic system or to the functional state of the HPA axis, is that both can be easily verified experimentally. To sum up, the data of the present research consist of an experimental confirmation of persistent alterations in the CNS functional state following an acute treatment to chlorphenvinphos, an organophosphorus pesticide. The alterations manifest themselves in the form of reduced behavioral sensitivity to amphetamine and reduced susceptibility to become behaviorally sensitized by repeated amphetamine treatment. Based on the literature data, it has been proposed that the CVP-induced alterations consist of either an increased functional tone of the cholinergic system or a reduced sensitivity of the HPA axis.

\section{ACKNOWLEDGEMENTS}

The authors are grateful to Elżbieta Jabłońska for her excellent technical assistance.

\section{REFERENCES}

1. Abou-Donia MB. Organophosphorus ester-induced chronic neurotoxicity. Arch Environ Health 2003;8:484-97.

2. Gralewicz S, Lutz P, Szymczak W. Hyposensitivity to amphetamine following treatment to chlorphenvinphos. Protection by amphetamine pretreatment. Acta Neurobiol Exp 2000;60:203-7.

3. Vanderschuren LJ, Kalivas PW. Alterations in dopaminergic and glutamatergic transmission in the induction and expression of behavioral sensitization: a critical review of preclinical studies. Psychopharmacology 2000;151:99-120.

4. Antelman SM, Caggiula AR, Kocan D, Knopf S, Meyer D, Edwards DJ, et al. One experience with "lower" or "higher" stressors, respectively, enhances or diminishes responsiveness to haloperidol weeks later: implications for understanding drug variability. Brain Res 1991;566:276-83.

5. Antelman SM, Soares JC, Gershon S. Time-dependent sensitization - possible implications for clinical pharmacology. Behav Pharmacol 1997;8:505-14.

6. Ellman GL, Courtney KD, Andres V Jr, Feather-Stone RM. A new and rapid colorimetric determination of acetylcholinesterase activity. Biochem Pharmacol 1961;7:88-95.

7. Winer BJ. Statistical Principles in Experimental Design. New York: Mac Graw Hill Book Company;1962.

8. Gralewicz S, Soćko R. Effects of a single treatment to chlorphenvinphos, an organophosphorous insecticide, on hot-plate behaviour in rats. Pol J Occup Med 1989;3:215-22.

9. Lutz P, Gralewicz S, Kur B, Wiaderna D. Amphetamine- and scopoloamine-induced lcomotor activity following treatment with chlorphenvinhpos or chlorphyriphos in rats. Int J Occup Med Environ Health 2005;18:115- 25.

10. Overstreet DH, Miller CS, Janowsky DS, Russel RW. Potential animal model of multiple chemical sensitivity with cholinergic supersensitivity. Toxicology 1996;111:119-34.

11. Nijholt I, Farchi N, Kye M, Sklan EH, Shoham S, Verbeure B, et al. Stress-induced alternative splicing of acetylcholinesterase results in enhanced fear memory and long-term potentiation. Mol Psychiatry 2004;9:174-83.

12. Meshorer E, Erb C, Gazit R, Pavlovsky L, Kaufer D, Friedman A, et al. Alternative splicing and neuritic mRNA translocation under long-term neuronal hypersensitivity. Science 2002;295:508-12.

13. Deroche V, Marinelli M, Maccari S, Le Moal M, Simon H, Piazza PV. Stress-induced sensitization and glucocorticoids. I. Sensitization of dopamine-dependent locomotor effects of amphetamine and morphine depends on stress-induced corticosterone secretion. J Neurosci 1995;15:7181-8. 
14. Reid MS, Ho LB, Tolliver BK, Wolkowitz OM, Berger SP. Partial reversal of stress-induced behavioral sensitization to amphetamine following metyrapone treatment. Brain Res 1998;783:133-42.

15. Marinelli M, Piazza PV. Interaction between glucocorticoid hormones, stress and psychostimulant drugs. European J Neurosci 2002;16:387-94.

16. Osicka-Koprowska A, Lipska M, Wysocka-Paruszewska B. Effects of chlorfenvinphos on serum corticosterone and aldosterone levels in rats. Arch Toxicol 1984;55:68-9.

17. Kassa J, Bajgar J. Treatment of the stressogenic effect of dichlorvos. Sb Ved Pr Lek Fak Karlovy Univerziti Hradci Kralove 1994;37:29-32.

18. Gralewicz S, Lutz P, Kur B. Pretreatment with footshock alters some effects of subsequent organophosphate treatment. NeuroToxicology 2005;26:159-71.

19. Gądek-Michalska A, Bugajski J. Repeated handling, restraint, or chronic crowding impair the hypothalamic-pituitary-adrenocortical response to acute restraint stress. J Physiol Pharmacol 2003;54:449-59.

20. Bugajski A, Gądek-Michalska A, Bugajski J. A single corticosterone pretreatment inhibits the hypothalamic-pituitary-adrenal responses to adrenergic and cholinergic stimulation. J Physiol Pharmacol 2001;52:313-24.

21. Liberzon I, Krstov M, Young EA. Stress-restress: effects on ACTH and fast feedback. Psychoneuroendocrinology 1997;22:443-53.

22. Garcia A, Marti O, Valles A, Dal-Zotto S, Armario A. Recovery of the hypothalamic-pituitary-adrenal responses to stress. Effects of stress intensity, stress duration and previous stress treatment. Neuroendocrinology 2000;72:114-25.

23. Valles A, Marti O, Harbuz MS, Armario A. A single lipopolysaccharide administration is sufficient to induce a long-term desensi- tization of the hypothalamic-pituitary-adrenal axis. Neuroscience 2002;112:383-89.

24. Carobrez SG, Gasparotto OC, Buwalda B, Bohus B. Long-term consequences of social stress on corticosterone and IL-1 $\beta$ levels in endotoxin-challenged rats. Physiol Behav 2002;76:99-105.

25. Louvart H, Maccari S, Ducrocq F, Thomas P, Darnaudery M. Long term behavioural alterations in female rats after a single intense footshock followed by situational remainders. Psychoendocrinology 2005;30:316-24.

26. Kaufer D, Friedman A, Seidman S, Soreq H. Acute stress facilitates long-lasting changes in cholinergic gene expression. Nature 1998;393:373-77.

27. Kaufer D, Friedman A, Seidman S, Soreq H. Anticholinesterases induce multigenic transcriptional feedback response suppressing cholinergic neurotransmission. Chemico-Biological Interactions 1999;119120:349-60.

28. Kanter ED, Wilkinson CW, Radant AD, Petrie EC, Dobie DJ, McFall ME, et al. Glucocorticoid feedback sensitivity and adrenocortical responsiveness in posttraumatic stress disorder. Biol Psychiat 2001;50:238-45.

29. Yehuda R, Halligan SL, Golier JA, Grossman R, Bierer LM. Effect of trauma treatment on the cortisol response to dexamethasone administration in PTSD and major depressive disorder. Psychoendocrinology 2004;29:389-404.

30. Yehuda R, Southwick SM, Krystal JH, Bremner D, Charney DS, Mason JW. Enhanced suppression of cortisol following dexamethasone administration in posttraumatic stress disorder. Am J Psychiat 1993;150:83-6. 